\title{
Pericardial calcification with plain radiographic features of tuberculosis in a child: incidental finding and a case report
}

\author{
Sule MB ${ }^{1 *}$, Umar AU ${ }^{2}$, Gele $\mathrm{IH}^{3}$, $\mathrm{Umar}_{\mathrm{FK}}{ }^{3}$, Uzoma Gu ${ }^{3}$ and Aliyu $\mathrm{AZ}^{3}$ \\ ${ }^{1}$ Radiology Department, Usmanu Danfodiyo University, Sokoto. \\ ${ }^{2}$ Radiology Department, Gombe State University, Gombe. \\ ${ }^{3}$ Radiology Department, Usmanu Danfodiyo University Teaching Hospital, Sokoto.
}

*Correspondence Author: Sule Muhammad Baba, Department of Radiology, Usmanu Danfodiyo University, Sokoto. Received date: March 02, 2021; Accepted date: March 08, 2021; Published date: March 22,2021

Citation: Sule MB. Umar AU., Gele IH., Umar F.K., Uzoma Gu. and Aliyu A.Z. (2021) Pericardial calcification with plain radiographic features of tuberculosis in a child: incidental finding and a case report. Clinical Medical Reviews and Reports 3(4); DOI:10.31579/2690-8794/074

Copyright: (C) 2021 Sule Muhammad Baba, This is an open access article distributed under the Creative Commons Attribution License, which permits unrestricted use, distribution, and reproduction in any medium, provided the original work is properly cited.

\begin{abstract}
Tuberculous pericarditis is frequently reported as the primary cause of pericardial calcification and occurs in about $1-2 \%$ of individuals with pulmonary tuberculosis, this however is a rare finding in the Western world. This is a $12-$ year-old male child that was referred from a peripheral health care center for plain radiograph of the chest on account of cough, easy fatiguability, night sweats, loss of weight, loss of appetite and dyspnea most times on excersion for more than a month duration.

The plain chest radiograph demonstrated normal cardiac size with a cardiothoracic ratio of about 55/120, there is circumferential radio-opacity of calcic density around the peripheral walls of the heart; the pericardial calcification. The vascular pedicle appears slightly widened. The lung fields show extensive streaky opacities with cystic lung changes bilaterally more marked on the left lung field where consolidation, loss of lung volume and pleural effusion are also demonstrated. A two-dimensional echocardiography showed mild-moderate pericardial effusion, thickening of both visceral and parietal pericardium, and echogenic fond-like structures protruding in to the pericardial cavity. A diagnosis of pulmonary tuberculosis with features of tuberculous pericarditis in a 12-year-old male child was established. The patient has been placed on anti-tuberculous drugs, hematinic, and parents advised on good and adequate diet with adequate rehydration and strict drug compliance. Screening of the siblings and members of the family with close contact have also been emphasized. We report the radiographic features of pulmonary tuberculosis and pericardial calcification in a 12 -year-old male child due to its peculiar presentation.
\end{abstract}

Keywords: tuberculosis, pericarditis, constrictive, calcification

\section{Introduction}

Pericardial calcification is present in less than $25 \%$ of all cases of constrictive pericarditis, with the etiology of pericardial calcification been uncertain most times $[1,2]$. The true incidence of PC happens to be unknown [3, 4 and 5]. Tuberculosis is regarded a leading cause of pericarditis in some non-industrialized countries, in the United States however, it accounts for about $10 \%$ of cases of chronic constrictive pericarditis [6-8].

Tuberculous pericarditis presents clinically in three forms, these are: pericardial effusion, constrictive pericarditis, and a combination of constriction and effusion $[9,10]$. Tuberculous involvement of the heart as form of extrapulmonary tuberculosis is regarded as the second commonest from the central nervous involvement especially with respect to morbidity and mortality [11].

Constrictive pericarditis $(\mathrm{CP})$ is a relatively rare condition that is often caused by pericardial dysfunction following varying etiologies, and results in impaired cardiac function and associated with diastolic heart failure $[11,12]$. The presence of calcification often supports the diagnosis of $\mathrm{CP}$, but not all the patients with $\mathrm{CP}$ have pericardial calcification [13, 14 and15]. Previously the most common cause of CP is tuberculosis, however in modern terms, the common causes are open heart surgery and mediastinal irradiation [16]. Constrictive pericarditis is often caused by fibrosis and calcification of the pericardium, leading to loss of normal elasticity of the pericardium, these causes decreased diastolic filling of the heart, and right heart failure [13, 14].

Pericardial calcification as a lone entity is often asymptomatic, however, signs and symptoms can evolve due to underlying disease processes such as $\mathrm{CP}$, it however may (PC) occur in the absence of any constrictive physiology [17].

Pericardial calcifications are regarded as important sign of constrictive pericarditis which can be diagnosed and also confirmed following imaging, among which are computed tomography (CT), echocardiography and cardiac magnetic resonance imaging, however CT 
is a useful guide in the management and diagnosis of CP [13-15,18]. Pericardial calcification on plain chest radiograph is highly suggestive of $\mathrm{CP}$, the presence of $\mathrm{PC}$ on chest radiographs frequently implicates $\mathrm{CP}$ as the cause of symptoms irrespective of the extent of pericardial thickening [13, 19 and 20].

\section{Case Report}

This is a 12-year-old male child that was referred from a peripheral health care center for plain radiograph of the chest on account of cough, easy fatiguability, night sweats, loss of weight, and loss of appetite, weakness, occasional fever, chest pain and dyspnea most times on excersion for more than a month duration of onset.

The patient is the $6^{\text {th }}$ child in a non-nuclear family of 14 children, the father is a farmer while the mother a housewife and not gainfully employed.

The patient is conscious and alert, mildly pale, mild dehydration, mildly icteric, acyanosed, mild respiratory difficulty, no significant pedal and facial edema, no finger clubbing, but has mild elevation of the jugular venous pulse.

The blood pressure is about $125 / 90 \mathrm{mmHg}$, pulse rate is about 86 beats per minute, and respiratory rate is also about 28 cycles per minute. Reduced heart sound intensity, audible pericardial rub with reduced breath sounds bilaterally more marked on the left lung field distally.

The sputum gram stain showed gram-negative Mycobacterium tuberculosis, the erythrocyte sedimentation rate (ESR) was also elevated; $17 \mathrm{~mm} / \mathrm{hr}$.
The plain chest radiograph demonstrated normal cardiac size with a cardiothoracic ratio of about 55/120, there is circumferential radioopacity of calcic density around the peripheral walls of the heart; the pericardial calcification. The vascular pedicle appears slightly widened; see figure 1 a.

The lung fields show extensive streaky opacities with cystic lung changes bilaterally more marked on the left lung field where consolidation with increased opacification is demonstrated on the mid and lower zones with non-demonstration of the left costophrenic sulci in keeping with loss of lung volume and effusion. Compensatory hyperinflation noted on the left upper zone and the right lung field. The bony thorax and overlying soft tissue outline show normal appearances; see figure $1 \mathrm{~b}$.

A two-dimensional echocardiography showed mild-moderate pericardial effusion, thickening of both visceral and parietal pericardium, and echogenic fond-like structures protruding in to the pericardial cavity.

A diagnosis of pulmonary tuberculosis with features of tuberculous pericarditis in a 12-year-old male child was established.

The patient has been placed on anti-tuberculous drugs (rifampicin, isoniazid, ethambutol and pyrazinamide for a minimum of six months), corticosteroid for prevention of $\mathrm{CP}$, hematinic, and parents advised on good and adequate diet with adequate rehydration and strict drug compliance. Screening of the siblings and members of the family with close contact have also been emphasized.

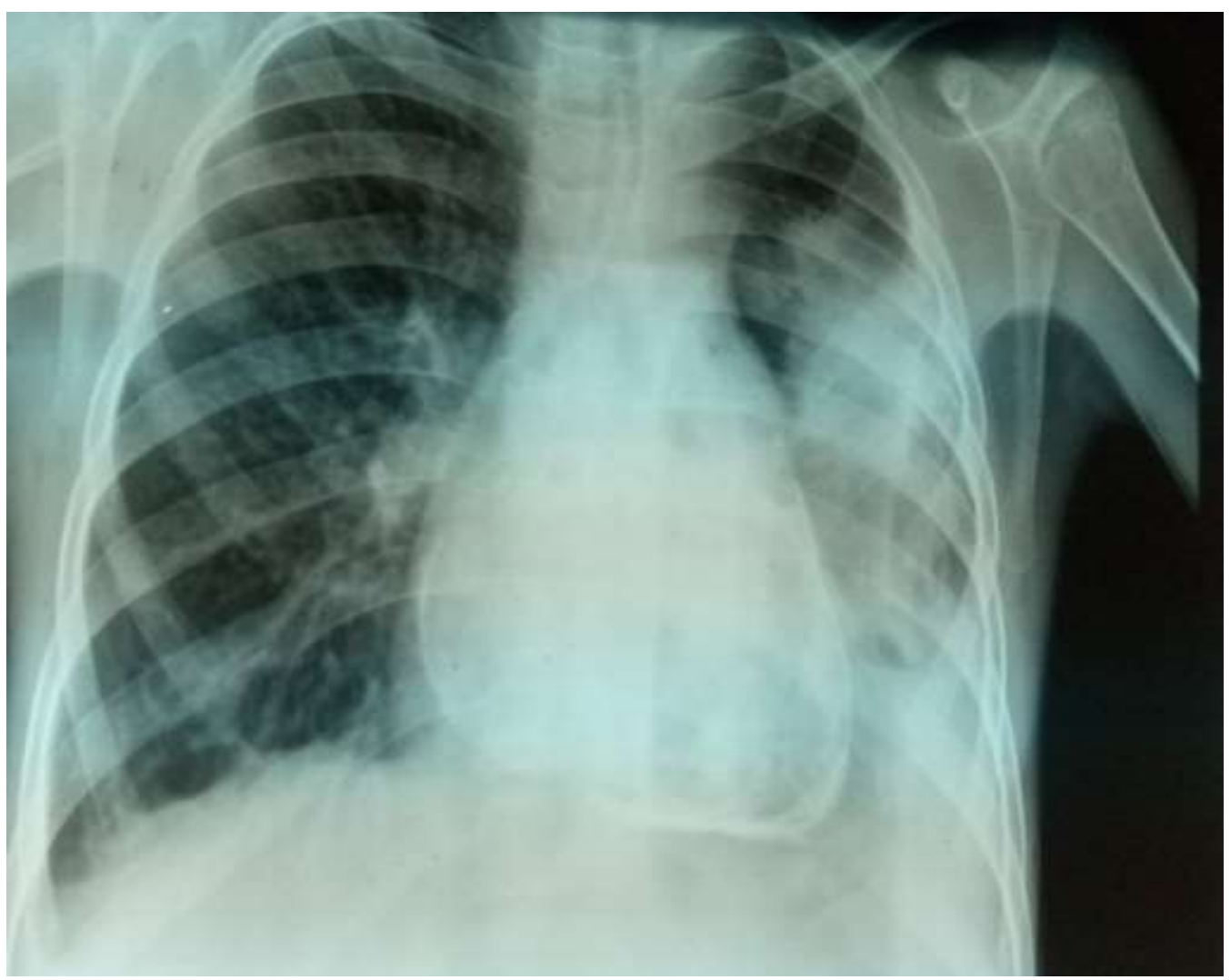

Figure 1a: Plain radiograph of the chest demonstrating a circumferential ring-like radio-opacity of calcific density at the peripheral walls of the heart; the pericardial calcification. The region of the superior mediastinum appears minimally widened; widened vascular pedicle. 


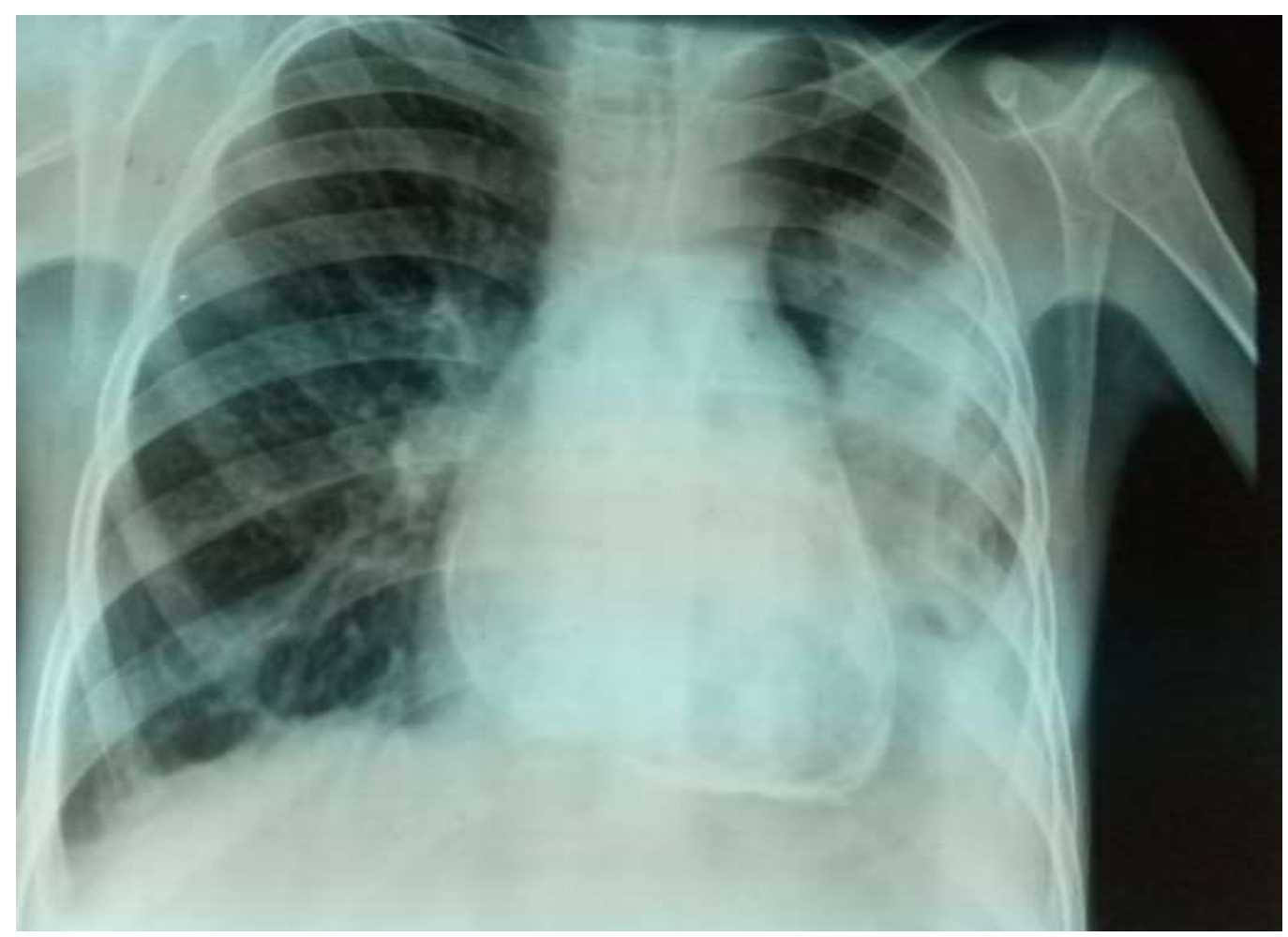

Figure 1b: Plain radiograph of the chest, demonstrating widespread streaky opacities with cystic lung changes more on the left lung field where consolidation and increased opacification (features of loss of left lung volume) with obscured left costophrenic angle; left pleural effusion. Compensatory hyperinflation noted on the left upper lung zone and right lung field.

\section{Discussion}

Tuberculous involvement of the heart as form of extrapulmonary tuberculosis is regarded as the second commonest from the central nervous involvement especially with respect to morbidity and mortality ${ }^{11}$. The index case had pulmonary tuberculosis with involvement of the heart, no feature to suggest central nervous involvement, thereby conforming to this literature.

Pericardial tuberculosis is regarded as a chronic fibrinous pericarditis characterized by granulomatous inflammation and caseous necrosis [9, 21]. The index case was confirmed of having the gram-negative Mycobacterium tuberculosis, which is a granulomatous inflammation, thereby conforming to these literatures.

Tuberculous pericarditis presents clinically in three forms, these are: pericardial effusion, constrictive pericarditis, and a combination of constriction and effusion $[9,10]$. The case under review had pericardial effusion and features of constrictive pericarditis (CP), thereby conforming to these literatures.

Pericardial calcification as a lone entity is often asymptomatic, however, signs and symptoms can evolve due to underlying disease processes such as $\mathrm{CP}$, it however may (PC) occur in the absence of any constrictive physiology [17]. The index case had features of CP and not asymptomatic.

Pericardial calcifications are regarded as important sign of constrictive pericarditis which can be diagnosed and also confirmed following imaging, among which are computed tomography (CT), echocardiography and cardiac magnetic resonance imaging, however CT is a useful guide in the management and diagnosis of CP [13-15,18]. The case under review was not an exception, he had chest radiograph and echocardiography, thereby conforming to these literatures.
Pericardial calcification can be detected on chest radiograph in almost $50 \%$ of cases of $\mathrm{CP}$, though extensive PC can be present without signs and symptoms of $\mathrm{CP}$, there are varying causes of $\mathrm{PC}$, tuberculosis has historically been the leading cause worldwide [22]. The index case was a confirmed case of tuberculosis, presented with plain chest radiographic features of PC and clinical signs and symptoms of tuberculosis and tuberculous pericarditis thereby conforming to this literature.

Echocardiography has been regarded as a sensitive diagnostic imaging modality for detecting pericardial effusion and intrapericardial abnormalities [23], the index case also benefitted from echocardiography, this demonstrated pericardial effusion, thickening and calcification of the pericardium, thereby conforming to these literatures.

Constrictive pericarditis results from fibrous thickening of the pericardium, this is most often accompanied with calcification thereby resulting in affectation of diastolic filling of the heart [24, 25], and the index case had pericardial calcification with features of reduced diastolic filling of the heart, thereby conforming to these literatures.

In tuberculous pericarditis, treatment is aimed at achieving three goals, these are eradicating the active Mycobacterium, relief of cardiac compression with adverse hemodynamic sequelae, and thirdly prevention of complications of maladaptive remodeling and healing, CP inclusive ${ }^{26}$. Similar treatment modalities which include institution of antibacterial agents, corticosteroid for $\mathrm{CP}$, institution of hematinic, adequate rehydration and close monitoring of patient and contact tracing were employed in the index case, thereby conforming to this literature.

\section{Conclusion}

Tuberculosis is regarded endemic in developing countries, patients presenting with features of pulmonary tuberculosis should be investigated by imaging and adequately monitored to prevent occurrence of 
extrapulmonary affectation like pericardial involvement, and this will reduce morbidity and mortality associated with such complications.

\section{References}

1. Ohri Raja, Salhiyyah K, Harding S, Ohri S. (2019) Pericardial calcification: A case report of a three-dimensional disease. Int $J$ Surg Case Rep. 57:152-154.

2. Cosyns B, Plein S, Nihoyanopoulos P, Smiseth O, Achenbach S, Andrade MJ. (2015) European Association of Cardiovascular Imaging (EACVI) position paper: multimodality imaging in pericardial disease. Eur. Heart J. Cardiovasc. Imaging. 16:12-31.

3. Shaw M, Pandey NN, Sharma A, Sharma S. (2008) Pericardial calcification: an uncommon presentation of rheumatic heart disease. BMJ Case Rep. 226435.

4. Bouwman RA, vanSchijindel RJ. (2009) Images in clinical medicine. Pericardial calcification noted long after Sydenham's chorea. $N$ Eng J Med. 361:1386.

5. George P, Badekila AK, Hegde N. (2020) Unusual Tick Mark Calcification on chest radiograph in rheumatic heart disease-CT imaging revealing pericardial calcification. J Clin Diagn Res. 2013; 7:787-788.

6. Yetkin U, Ilhan G, Calli AO, Yesil M, Gurbuz A. (2008) Severe Calcific Chronic Constrictive Tuberculous Pericarditis. Tex Heart Inst J. 35:224-225.

7. Bozbuga N, Erentug V, Eren E, Erdogan HB, Kirali K, Antal A, et al. (2003) Pericardiectomy for chronic constrictive tuberculous pericarditis: risks and predictors of survival. Tex Heart Inst J. 30:180-185.

8. Roberts WC. (2005) Pericardial heart disease: its morphologic features and its causes. Proc (Bayl Univ Med Cent). 18:38-55.

9. Mayosi BM, Burgess LJ, Doubell AF. (2005) Tuberculous Pericarditis. Circulation AHA. 112:3608-3616.

10. Strang JIG. (1982) Tuberculous pericarditis. In: Campbell GD, Seedat YK, Daynes G, eds. Clinical Medicine and Health in Developing Africa. Cape Town: David Philip. 145-149.

11. Mutyaba AK, Ntsekhe M. (2017) Tuberculosis and the heart. Cardiol Clin. 35:135-144.

12. Miranda WR, Oh JK. (207) Constrictive pericarditis: a practical clinical approach. Prog Cardiovasc Dis. 59:369-379.

13. Lee MS, Choi JH, Kim YC, Kim SW. (2014) Ring-shaped calcification constrictive pericarditis strangling the heart: a case report. Int J Emerg Med. 7:40.
14. Bogaert J, Francone M (2013) Pericardial disease: value of CT and MR imaging. Radiology. 267:340-356.

15. Senapati A, Isma'eel HA, Kumar A, Ayache A, Ala CK, Phelan D, et al. (2018) Disparity in spatial distribution of pericardial calcifications in constrictive pericarditis. Open Heart. 5: e000835.

16. Ling LH, Oh JK, Schaff HV, Danielson GK, Mahoney DW, Seward JB, et al. (1999) Constrictive pericarditis in the modern era: evolving clinical spectrum and impact on outcome after pericardiectomy. Circulation. 100:1380-1386.

17. Khalid N, Ahmad SA, Shlofmitz. (2020) Pericardial Calcification. Treasure Island (FL): Start Pearls Publishing.

18. Yared K, Baggish AL, Picard MH, Hoffmann U, Hung J (2010) Multimodality imaging of pericardial diseases. JACC Cardiovasc Imaging. 3:650-660.

19. Isner JM, Carter, ankoff MS, Konstam MA, Salem DN (1982) computed tomography in the diagnosis of pericardial heart disease. Ann Intern Med. 97:473-479.

20. Ling LH, Oh JK, Schaff HV, Danielson GK, Mahoney DW, Seward JB, et al. (2006) Calcific constrictive pericarditis: is it still with us? Ann Intern Med. 132:444-450.

21. Ntsekhe M, Mayosi BM, Gumbo T. (2012) Quantification of echodensities in tuberculous pericardial effusion using fractal geometry: a proof-of-concept study. Cardiovascular Ultrasound. 10:30.

22. Nayak MM, Potdar PV, Thakker HS. (2014) Tuberculous Pericardial Calcification. Journal of Evolution of Medical and Dental Sciences. 3:15614-15616.

23. Chang-Sheng K, Kuan-Rau C, Shao-Lin L, Chung-Peng L, HungTing C. (2003) Echocardiographic Features of Tuberculous Pericarditis. J Chin Med Assoc. 66:612-614.

24. Laudari S, Dhungel S, Gautam S, Dubey L, Prasad G, Bhattacharya R, et al. (2014) Densely calcified tuberculous constrictive pericarditis with concurrent active pulmonary tuberculosis infection. J Coll Med Sci-Nepal. 10:41-43.

25. Little WC, Freeman GL. (2006) Pericardial disease. Circulation. 113:1622-1632.

26. Isiguzo G, Bruyn ED, Howlett P, Ntsekhe M. (2020) Diagnosis and Management of Tuberculous Pericarditis: What is New? Curr Cardiol Rep. 22:2.

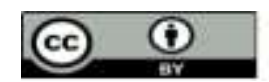

This work is licensed under Creative Commons Attribution 4.0 License

\author{
Ready to submit your research? Choose Auctores and benefit from: \\ * fast, convenient online submission \\ * rigorous peer review by experienced research in your field \\ * rapid publication on acceptance \\ * authors retain copyrights \\ * unique DOI for all articles \\ * immediate, unrestricted online access
}

At Auctores, research is always in progress.

Learn more www.auctoresonline.org/journals/clinical-medical-reviewsand-reports 